\title{
Politeness and Speech acts of Refusal and Complaint among Jordanian Undergraduate Students
}

\author{
Lana Kreishan*
}

Department of English Language and Literature, Al-Hussein Bin Talal University, Ma'an, Jordan

Corresponding Author: Lana Kreishan, E-mail: Lana_k300@yahoo.com

\section{ARTICLE INFO}

Article history

Received: October 28, 2017

Accepted: January 19, 2018

Published: July 01, 2018

Volume: 7 Issue: 4

Advance access: May 2018

Conflicts of interest: None

Funding: None

\begin{abstract}
This study investigated the refusal and complaint speech act strategies employed by Jordanian undergraduate EFL learners. Refusal and complaint data were collected using a discourse completion test and role-plays. The findings revealed that, as non-native speakers, the respondents preferred to use indirect semantic formulas. The most frequently used refusal strategies involved an explanation or excuse, apology, negative ability, postponement or adjuncts to refusals. Conveying hints, requests, and annoyance constituted the preferred strategies for expressing complaints. The Jordanian students utilized these strategies quite often because the strategies are less direct and more polite. The analysis revealed similarities between the strategies used by the sample EFL learners and the strategies used by native English speakers. Because speech acts depend on standard cultural norms and practices, it is important for EFL learners to understand English-speaking social settings in order to avoid pragmatic failure and miscommunication. EFL instructors should therefore emphasize linguistic pragmatics for learners to assimilate into an English speaking cultural environment and maintain clear and unambiguous communication.
\end{abstract}

Key words: Pragmatics; refusal; complaint; speech act; seperation.

\section{INTRODUCTION}

Communication is essential in the sharing of thoughts, feelings, and information between individuals, and it serves to maintain associations and relationships. Communication may be linguistic or nonlinguistic, including body language and facial expressions (Moaveni, 2014). Therefore, effective communication requires both linguistic knowledge and a deep understanding of the cultural and social factors relevant to the situation. Human communication is dynamic, having evolved over a long period, with women and men utilizing it in different ways for various purposes (Moaveni, 2014). In one study, Hungarian female university students tended to use indirect strategies to express their disagreement more frequently than their male counterparts did (Koczogh, 2012). Using such speech acts is an essential element of communicative competence, requiring individuals to know how, when, and where to perform speech acts for achieving effective communication, because failure to do so may result in cultural conflicts and miscommunication.

As a lingua franca, English is no longer limited to specific speakers in certain countries. Many new varieties of the language have emerged, and most of the world now belongs to a de facto English-speaking community. Membership in this community in ESL or EFL contexts requires both linguistic and communicative competence.

Regarding communicative competence, individuals employ various speech acts to achieve their communication goals.
Because people may have different feelings about the same situation, such as unhappiness, dissatisfaction, or annoyance, they engage in different speech acts to express those feelings. Unappealing situations trigger expressions of complaint, which depend on the level of dissatisfaction and other social factors. A complaint as a speech act is considered an expression of annoyance, frustration, or unhappiness about past or current actions that affect the speaker unfavorably (Olshtain and Weinbach, 1993, cited in Zhang, 2001). A complaint is therefore a speech act performed when one is confronted with a problem with the intention of improving the situation. According to Zhang (2001:8), the complaint speech act "intrinsically threaten[s] both [the] negative and positive face of the hearer."

\section{Statement of the Problem}

Pragmatics is crucial for learning a second language (L2) because learners are expected to understand the rules that govern the use of the language. However, it is evident from previous research that L2 learners utilize a pragmatic system different from that of native speakers (NSs). In the process of learning a new language, foreign language learners tend to refer to their native social and cultural norms (cf. Cortijo, 2015). This allows for the possibility of differences in the performance of speech acts between NSs and nonnative speakers (NNSs). Refusals and complaints are particularly complex in nature because they depend on social and cultural variables such as education, gender, and social status. There- 
fore, refusals and complaints may be difficult to express or perceive properly, especially by EFL students prone to employing strategies from their native language due to a lack of pragmatic knowledge. As Tanck (2002) argued, refusals and complaints require high pragmatic competence, which makes them naturally more difficult for NNSs than for NSs.

The influence of the pragmatics of one's first language (L1) may affect one's L2 pragmatics to a great extent. Similarities in pragmatics enhance learning and promote high L2 performance, whereas differences may trigger negative transfer. Pragmatic transfer has been considered extensively in research, given that learners' comprehension and production of L2 pragmatics are influenced by their pragmatic knowledge of other languages (Kasper, 1992).

\section{Aims of the Study}

Learning a language is essentially an aspect of learning about another culture. The current study aimed to:

1. Identify the refusal and complaint strategies used by Jordanian EFL undergraduate students (regarding strategy use and patterns);

2. Highlight the factors that govern their choice of language;

3. Examine the choice of language items by Jordanian students with respect to the clarity of their communicative features.

\section{Speech Act of Refusal}

The speech act of refusal has been identified as the main challenge for EFL learners because it can cause undue offense and communication breakdown. As a face-threatening act, it is particularly sensitive. In most cases, EFL students are more likely than NSs to offend their interlocutors in the process of performing the act of refusal, because the extant obstacle of linguistic proficiency is compounded by the threatening nature of the speech act (Flor and Juan, 2011). A refusal is a dispreferred response that contradicts the expectations of interlocutors; hence pragmatic competence is necessary to carry it out appropriately.

Austin (1962) categorized speech acts as locutionary, illocutionary, and perlocutionary; referring to the utterance itself, the intended meaning of the utterance, and the effect of the utterance, respectively (reviewed in Mofidi and Shoushtari, 2012). Most studies have indicated that speech acts can be realized either directly or indirectly, but that they are mostly performed indirectly to "soften the blow". Therefore, according to Searle (1969), the indirect performance of a speech act in its linguistic form does not clearly represent the speaker's intention, thus requiring the addressee to decipher the intended meaning of the utterance in a particular context (cf. Mofidi and Shoushtari, 2012).

The speech act of refusal has been thoroughly studied in inter-language and multicultural pragmatic linguistics. It always takes the form of a negative response to acts such as invitations, offers, requests, and suggestions. A refusal can generally be considered a commissive speech act, although exceptions are possible in situations where the participants may not be aware of the outcome (see review in Sattar et al., 2011).
A study on the performance of refusal between Japanese EFL learners and American native English speakers showed that there was first an expression of regret, then an excuse, and finally an alternative suggestion. However, other studies have indicated that Japanese EFL speakers and native English speakers differ in the semantic formulas they use, their frequency, and the content of the expressions (cf. Beebe et al., 1990). Although the Japanese speakers produced the same semantic components as the NSs did, the quality of their utterances differed. Similar studies on the speech act of refusal as performed by Chinese EFL learners have indicated that direct refusal is not a common strategy, regardless of the participants' linguistic background (Moaveni, 2014). Cultural background can still influence the act of refusal; for instance, the expression of regret common among native English speakers is not generally produced by Chinese EFL speakers (Moaveni, 2014).

According to the taxonomy of Beebe et al. (1990) (cf. Ren, 2012; Moaveni, 2014), refusal strategies can be divided into semantic formulas and adjuncts to refusals. Formulas comprise a set of expressions functioning as refusals, whereas adjuncts are expressions that merely supplement refusals and cannot function as refusals on their own. Studies have reported that semantic formulas can realize refusals directly or indirectly. The direct mode comprises both the performative semantic formula, in which the refusal act is explicitly expressed, and the nonperformative negative willingness to express oneself. The indirect mode comprises acts used to mitigate a direct refusal by expressing regret, giving a reason for the refusal, or providing an alternative (Moaveni, 2014). In studies on speech act strategies, refusals are coded according to their order (position of semantic formula or adjunct), frequency (number of occurrences of refusal), and content (semantic formula or adjunct).

In investigating the sociocultural transfer of the performance of refusal, Al-Issa (2003) found three areas affected by transfer in Jordanian EFL learners: the choice of semantic formulas, content of semantic formulas, and length of responses. Other factors that affected transfer based on interview data were pride in their L1, their perception of the L2, and religion.

Al-Shboul and Huwari (2016) examined the similarities and differences in the performance of refusal between Jordanian and American male groups and demonstrated the significance of cultural norms and values. The findings revealed that both groups preferred indirect strategies such as providing an explanation, adjuncts to refusals, and apologies, although the American group was more direct in their refusals overall.

Moaveni (2014) compared the refusal strategies used by American undergraduate students and a group of international students. He found that the American sample used more direct strategies accompanied by gratitude semantic formulas, whereas the international sample tended to use regret and explanation. Compared with the Americans, the international sample tended to provide reasons that were more specific. The study also showed that the Americans tended to use different semantic formulas and indirect strategies (expressing regret, providing reasons, and using adjuncts to refusals) if their interlocutor was a friend. 
Eshreteh (2015) examined the differences and similarities in the performance of refusal between samples of Palestinians and Americans. The analysis showed that the Palestinians adopted a refusal strategy of "marginally touching the point," with emphasis placed on restoring and maintaining relationships people (p. 187). By contrast, the Americans tended to resolve the matter in question, and the number of employed refusal strategies was economically chosen.

\section{Speech Act of Complaint}

The speech act of complaint is performed when an individual reacts with annoyance and displeasure to actions that have influenced them unfavorably (Olshtain and Weinbach, 1987, cited in Tanck, 2012). As with a refusal, a complaint is face threatening; therefore, it is often realized through indirect strategies. Studies on the speech act of complaint as performed by NSs and NNSs (cf. Olshtain and Weinbach, 1987, cited in Tanck, 2012) have reported that, regardless of the L1, they express disapproval, complaints, accusations, and warnings, as well as threats that avoid the extremes of appearing too confrontational and too soft. In another study on American native English speakers and Korean EFL speakers (Murphy and Neu, 1997, reviewed in Tanck, 2012), there were significant similarities in the two groups' treatment of certain aspects of the speech act, such as the justification, explanation of the purpose, and proposal of an alternative solution, although they differed in the production of the complaint. In that study, the NSs seemed to produce complaints, whereas their Korean EFL counterparts produced some form of criticism that might cause offense in an American context.

Study findings reviewed in Baba (2010) indicate that, between native English speakers and German EFL speakers, the NSs were more conciliatory and employed less direct strategies. Japanese EFL learners in Tatsuki (2000, cited in Baba, 2010) used less severe complaints in their L1 than in English in the same context, due to a lack of competency in downgrading the complaints. Baba found that Japanese EEL learners tended to be less aggressive in expressing their annoyance in English than in Japanese, and there was evidence of negative transfer from their L1.

Other interlingual studies have indicated that strategies for performing the speech act of refusal or complaint differ according to the context as well as the gender and status of the interlocutors. This raises the question of what overarching principle governs speech in a multicultural setting. Studies on complaints produced by native English speakers and Danish EFL speakers (Trosborg, 1995, reviewed in Chen et al., 2011) have suggested that some researchers examine the similarities and differences between languages, whereas others are more concerned with identifying the transfer patterns between the L1 and L2. In English and Danish, speakers implement similar complaint strategies (Trosborg, 1995). Annoyance seems to occur in both languages, but strategies such as expressions of accusations, hints, and blame are less frequent. Other studies have found, for instance, that German EFL speakers express direct complaints more often than native English speakers do (House and Kasper, 1981, reviewed in Chen et al., 2011).
Al-Shorman (2016) investigated the complaint strategies used by two groups of Jordanian and Saudi male undergraduate students. The main strategies entailed exhibiting calmness and rationality (e.g., by expressing an inquiry, request, or self-blame), offensive acts (e.g., by expressing protest, a challenge, or a threat), opting out (e.g., by expressing dissatisfaction or irony, and appealing to religion), and direct complaint strategies. Calmness and rationality, the least threatening and most indirect strategy, was the most frequently used, possibly owing to the strong influence of their respective religious beliefs and cultural norms of politeness. Both groups elaborated on their complaints to reduce ambiguity, but the Saudi respondents employed more direct strategies. Despite cultural differences, similarities in the employed strategies provide evidence for the universality of the speech act of complaint.

Bikmen and Marti (2013) showed that expressions of requests, hints, and annoyance were frequent strategies used by the three samples in their study on differences in complaint strategies used by Turkish EFL learners, Turkish NSs, and native English speakers. There were similarities in the use of strategies to express hints, ill consequences, and threats between the Turkish EFL learners and native English speakers. Their results supported the idea that some complaint strategies are culturally specific, whereas others are multi-cultural and potentially universal.

In a study on the complaint strategies used by Chinese ESL students and American students, Zhang (2001) found an influence of Chinese culture on the Chinese students' strategies. For example, there was evidence of the influence of Confucianism on their complaints, and they borrowed equivalent words and phrases from Chinese to express complaints in English (e.g., "I think"). One similarity found between the samples was that the Chinese students used more justification and explanation in situations where the speaker and the listener knew each other, for maintaining politeness and indirectness to save the listener's face.

There are certainly differences in the production of complaints and refusals between EFL speakers and native English speakers, irrespective of the EFL speakers' native language. For instance, refusals by Chinese and Japanese EFL speakers have been found to be indirect and/or vague, as well as lacking an excuse, which is expected in an American cultural context (Moaveni, 2014). By contrast, Korean EFL speakers have been found to express complaints with direct criticism that is perceived as interaction-ending in other cultural contexts. Refusals and complaints require a high degree of pragmatic competence because they lie between very narrow margins of appropriateness. Therefore, it is clear that pragmatics should be taught to EFL students to enable them to use the target language as they wish without running afoul of said margins.

Knowledge of interlanguage pragmatics is essential for understanding the acquisition and use of linguistic patterns by L2 learners. Pragmatic competence on their part is required, because a lack of knowledge about speech act strategies and patterns when people from different cultures communicate may cause intercultural and interethnic communication breakdowns (Sattar, et al., 2011). Improving EFL students' prag- 
matic knowledge is therefore crucial, and EFL teachers should be at the forefront of pragmatic education (Shokouhi and Rezaei, 2015). Sometimes, intercultural miscommunications can cause learners to fall back to their sociocultural L1 practices in the process of performing speech acts in using a foreign language, which is a form of pragmatic transfer. To combat this, teachers should improve EFL students' understanding of the scope of interaction and the rules of politeness within the context of the target culture. In an EFL context, learners have limited opportunities to communicate in English outside their respective education systems, which take the traditional approach of teaching the form of the language over the meaning.

\section{METHODS}

\section{Participants}

Thirty-four students (12 male and 22 female) majoring in English language at Al-Hussein Bin Talal University participated in this study investigating their pragmatic competence in the use of refusal and complaint strategies. The ages of the participants ranged between 20 and 23 years. Most of them were third- and fourth-year undergraduate students who recruited based on expected advanced levels of linguistic and communicative competence.

\section{Measures and Procedure}

In the present study, data were collected through two types of instrument: a written discourse completion test (DCT) and group discussion. The instruments were used to measure the students' ability to implement refusal and complaint strategies fluently and properly in various situations. The DCT for refusals consisted of 14 situations and was adopted from Alemi and Tajeddin (2013) and Ren (2012). The first six situations, obtained from Alemi and Tajeddin (2013), focused on different contexts (e.g., educational, workplace, and daily life). The remainder addressed professor- student situations and student- student situations (Table 1) that ivoloved four types of refusals: a refusal of requests, refusal of suggestions, refusal of invitations, and refusal of offers.

The DCT for complaints was adopted from Bilkmen and Marti (2013). The items consisted of 10 everyday situations, such as a mobile phone malfunctioning, being at the cinema, facing an angry father, and having a noisy neighbor, with a brief description of each one (Table 2). The situations encompassed social relationships of relative distance (-D familiar; +D stranger) and power (+P higher status; -P lower status; $=$ P equal status) between the interlocutors.

The DCT and a form for collecting demographic information (e.g., gender, age, year of study) were distributed to the participating students during a class in which they were all enrolled in 2015 (conversation in English). The research aims and particular instructions were provided. The respondents were encouraged to respond according to each of the scripted situations and not to think about their responses excessively. After submitting their test, they were asked to form small groups of two to three students to discuss the appropriateness of their responses and potentially give additional responses. The students were then asked to roleplay each situation.
Table 1. Descriptions of refusal situations.

\begin{tabular}{|c|c|c|}
\hline Situation Summary & Distance & Power \\
\hline $\begin{array}{l}\text { 1. Cleaner breaking antique vase in } \\
\text { office. }\end{array}$ & $-\mathrm{D}$ & $+\mathrm{P}$ \\
\hline $\begin{array}{l}\text { 2. Old friend suggesting to go to work } \\
\text { in your car every day. }\end{array}$ & $-\mathrm{D}$ & $=\mathrm{P}$ \\
\hline $\begin{array}{l}\text { 3. Professor inviting his student to } \\
\text { lunch. }\end{array}$ & $-\mathrm{D}$ & $+\mathrm{P}$ \\
\hline $\begin{array}{l}\text { 4. Careless classmate asking for your } \\
\text { lecture notes. }\end{array}$ & $-\mathrm{D}$ & $=\mathrm{p}$ \\
\hline $\begin{array}{l}\text { 5. Colleague inviting you to an art } \\
\text { gallery. }\end{array}$ & $-\mathrm{D}$ & $=\mathrm{P}$ \\
\hline $\begin{array}{l}\text { 6. Older sister inviting you to a dinner } \\
\text { party. }\end{array}$ & $-\mathrm{D}$ & $=\mathrm{P}$ \\
\hline $\begin{array}{l}\text { 7. Tutor asking student to give a } \\
\text { presentation. }\end{array}$ & $-\mathrm{D}$ & $+\mathrm{P}$ \\
\hline $\begin{array}{l}\text { 8. Classmate asking for lecture notes } \\
\text { even though you need them. }\end{array}$ & $-\mathrm{D}$ & $=\mathrm{P}$ \\
\hline $\begin{array}{l}\text { 9. Tutor inviting you to a farewell } \\
\text { party but you are unable to attend. }\end{array}$ & $-\mathrm{D}$ & $+\mathrm{P}$ \\
\hline $\begin{array}{l}\text { 10. Classmate asking to go to a } \\
\text { restaurant even though you don't have } \\
\text { enough money. }\end{array}$ & $-\mathrm{D}$ & $=\mathrm{P}$ \\
\hline $\begin{array}{l}\text { 11. Tutor suggesting an optional } \\
\text { course to attend that you don't like. }\end{array}$ & $-\mathrm{D}$ & $+\mathrm{P}$ \\
\hline $\begin{array}{l}\text { 12. Classmate suggesting to skip a } \\
\text { class to watch a movie. }\end{array}$ & $-\mathrm{D}$ & $=\mathrm{P}$ \\
\hline $\begin{array}{l}\text { 13. Tutor offering a piece of cake } \\
\text { whose flavor you don't like. }\end{array}$ & $-\mathrm{D}$ & $+\mathrm{P}$ \\
\hline $\begin{array}{l}\text { 14. Classmate offering a piece of cake } \\
\text { even though you are full. }\end{array}$ & $-\mathrm{D}$ & $=\mathrm{P}$ \\
\hline
\end{tabular}

Table 2. Descriptions of complaint situations.

\begin{tabular}{lll}
\hline Situation Summary & Distance & Power \\
\hline $\begin{array}{l}\text { 1. Customer discovering that a new } \\
\text { phone they bought is broken. }\end{array}$ & $+\mathrm{D}$ & $=\mathrm{P}$ \\
$\begin{array}{l}\text { 2. Someone making too much noise } \\
\text { while watching a movie in the cinema. }\end{array}$ & $+\mathrm{D}$ & $=\mathrm{P}$ \\
$\begin{array}{l}\text { 3. Sister traveling to Canada forgot to } \\
\text { call her sister/brother }\end{array}$ & $-\mathrm{D}$ & $=\mathrm{P}$ \\
$\begin{array}{l}\text { 4. Friends watching a TV program } \\
\text { about a celebrity that one of the } \\
\text { friends hates. }\end{array}$ & $-\mathrm{D}$ & $=\mathrm{p}$ \\
$\begin{array}{l}\text { 5. Father is angry because son hasn't } \\
\text { found a job. }\end{array}$ & $-\mathrm{D}$ & $+\mathrm{P}$ \\
$\begin{array}{l}\text { 6. Car splashing dirty water on a } \\
\text { pedestrian. }\end{array}$ & $+\mathrm{D}$ & $=\mathrm{P}$ \\
7. Neighbor's son leaving trash near & $-\mathrm{D}$ & $+\mathrm{P}$ \\
your front door. & & \\
8. Professor refusing to let a student \\
take an exam because he is late. \\
$\begin{array}{l}\text { 9. Professor forgetting to mark } \\
\text { assignments that are part of a test the } \\
\text { following week. }\end{array}$ \\
\begin{tabular}{l} 
10. Neighbor having a party late at night. \\
\hline
\end{tabular} & $-\mathrm{D}$ & $-\mathrm{P}$ \\
\end{tabular}




\section{Data Analysis}

For the complaint data, the coding scheme used in Bikmen and Marti (2013) (cf. Trosborg [1995]) was applied
(Table 3). The strategy of expressing blame was considered the most direct, whereas that of providing hints was the most indirect. The coding scheme for the refusal data was main-

Table 3. Coding scheme for complaint strategies

\begin{tabular}{|c|c|c|}
\hline Category & Strategy & Example (s) \\
\hline & Str. 1 Opting out & N/A I would say nothing \\
\hline $\begin{array}{l}\text { Cat. } 1 \\
\text { No explicit reproach }\end{array}$ & Str. 2 Hints & Don't see much of you these days, do I? \\
\hline \multirow[t]{2}{*}{ Cat II. Expression of disapproval } & Str. 3 Annoyance & $\begin{array}{l}\text { You know I don't like dust, I'm allergic to dust, Didn't you } \\
\text { know it? }\end{array}$ \\
\hline & Str. 4: Ill consequences & Now I will probably lose my insurance. \\
\hline \multirow[t]{2}{*}{ Cat. III. Accusation } & Str. 5: Indirect & $\begin{array}{l}\text { Look at the mess, haven't you done any cleaning up for the } \\
\text { last week? }\end{array}$ \\
\hline & Str. 6: Direct & $\begin{array}{l}\text { You used to do the cleaning up all the time. What's up with } \\
\text { you now? }\end{array}$ \\
\hline \multirow[t]{2}{*}{ Cat. IV: Blame } & Str. 7: Modified blame & $\begin{array}{l}\text { "You could have said so, I mean, if you had so much to do." } \\
\text { And "it's boring to stay here and I hate living in a mess, } \\
\text { anyway you ought to clean up after you." }\end{array}$ \\
\hline & $\begin{array}{l}\text { Str. 8: Explicit blame (behavior) } \\
\text { Str. 9: explicit blame (person) }\end{array}$ & $\begin{array}{l}\text { "You never clean up after yourself, I'm sick and tired of it." } \\
\text { "Mete, (swear word) really, one can never trust you a damn. }\end{array}$ \\
\hline \multirow[t]{2}{*}{ Cat. V: Directive acts } & Str. 10: Request for repair & $\begin{array}{l}\text { "Would you mind doing your share of the duties as soon as } \\
\text { possible?" }\end{array}$ \\
\hline & Str. 11: Threat. & $\begin{array}{l}\text { "I shall be leaving soon (if you don't do your share of the } \\
\text { cleaning)." }\end{array}$ \\
\hline
\end{tabular}

Table 4. Coding Scheme for Refusal Strategies

\begin{tabular}{|c|c|c|}
\hline Category & Strategy & Example (s) \\
\hline Direct Refusal & $\begin{array}{l}\text { a. Direct No } \\
\text { b. Negative ability }\end{array}$ & $\begin{array}{l}\text { No. } \\
\text { I can't make it. }\end{array}$ \\
\hline Indirect Refusal & $\begin{array}{l}\text { a. Reason/Explanation } \\
\text { b. Postponement } \\
\text { c. Apology/Regret } \\
\text { d. Alternative } \\
\text { e. Request for additional information } \\
\text { f. Attempt to dissuade the interlocutor: } \\
\text { - Negative consequence } \\
\text { - Criticize } \\
\text {-Let interlocutor off the hook } \\
\text { - Request for empathy } \\
\text { g. Conditional acceptance } \\
\text { h. Indefinite reply } \\
\text { i. Repetition of part of previous discourse } \\
\text { j. Promise } \\
\text { k. Wish } \\
\text { 1. Avoidance: } \\
\text {-non-verbal } \\
\text {-verbal }\end{array}$ & $\begin{array}{l}\text { I need it, too. } \\
\text { Is it possible I do it next time? } \\
\text { I am sorry. } \\
\text { You could ask someone else. } \\
\text { Which movie? } \\
\text { I thought I will ruin your plan with my presentation with little } \\
\text { preparation. } \\
\text { Last time I tried to borrow your notebook, why didn't you lend } \\
\text { it to me? } \\
\text { Don't worry; That's ok. } \\
\text { I hope you can understand. } \\
\text { If you really need it, I can go. } \\
\text { I don't know if I can come to your party. } \\
\text { Tomorrow? } \\
\text { I will help you if I can. } \\
\text { I wish I could help. } \\
\text { Silence, hesitation and departure } \\
\text { Topic switch and postponement }\end{array}$ \\
\hline Adjuncts to Refusals & $\begin{array}{l}\text { a. Statement of positive opinion } \\
\text { b. Willingness } \\
\text { c. Agreement } \\
\text { d. Statement of empathy } \\
\text { e. Preparator } \\
\text { f. Gratitude } \\
\text { g. pause fillers }\end{array}$ & $\begin{array}{l}\text { That's a good idea. } \\
\text { I'd love to go. } \\
\text { Yes/Ok. } \\
\text { I know it's quit important for you to prepare exam. } \\
\text { I'll be honest with you. } \\
\text { Thank you for your invitation. } \\
\text { Well }\end{array}$ \\
\hline
\end{tabular}


ly adapted from Ren (2012), who adopted the widely used taxonomy of Beebe et al. (1990). Some of the Beebe et al. items not used by Ren were reinserted in the study, such as pause fillers and avoidance. To ensure the correct categorization of the data, two raters majoring in linguistics analyzed and categorized random samples. Their classifications were highly consistent.

\section{RESULTS}

A descriptive analysis of refusal strategy formulas was performed. The frequencies of strategies used in each situation were computed. The total for each strategy in all situations was then calculated. Table 5 shows the frequencies of the refusal strategies used in our sample. The most frequently used strategy entailed an indirect refusal with an explanation, and the least common strategies involved requests for additional information and preparatory. Other frequently used strategies included an indirect refusal with an apology, claim of inability, and postponement. Adjuncts to refusals such as expressions of agreement and gratitude and statements of negative opinion were deemed as more polite ways of performing refusals.

The complaint data revealed, as presented in Table 6, that the most common semantic formulas used by the EFL learners involved hints, requests for repair, and annoyance. The least common formulas entailed consequence, explicit blame, and opting out.

\section{DISCUSSION}

The findings of the current study revealed pragmatic differences in the verbal utterances and semantic formulas used to perform refusals and complaints by Jordanian undergraduate EFL learners. Comparing these findings with those reported in studies involving native English speakers revealed a clear effect of socio-cultural differences on the performance of these speech acts. The comparison was performed to demonstrate the peculiarities of Arabic culture and to elucidate the pragmatic competence of the sample in this study. The results of this study show that the respondents, as non-native speakers, preferred to use indirect semantic formulas in the performance of refusal. As mentioned, the most frequently used refusal strategies entailed an explanation or excuse, apology, negative ability, postponement, or adjuncts to refusals. NNSs are generally more likely than NSs to use indirect refusal strategies (cf. Al-Shboul and Huwari, 2016). Although there were similarities in the refusal strategies used by the NNSs and NSs (such as those involving an explanation, negative ability, or apology), the Arabic context of cultural values clearly affected our sample's choice of strategies and semantic formulas. In Al-Shboul and Huwari (2016), the American sample's preferred strategies entailed, in order, an explanation, gratitude, and an apology. Although both groups implemented the explanation strategy, the Jordanian sample was less direct in giving reasons for their refusals. In the current study, the most common semantic formulas used for refusals involved the polite and nonthreatening apology and explanation.
The findings are also in line with those of Al-Issa (2003), who showed that EFL learners tend to use more semantic formulas than native English speakers do when performing refusals. Another finding is that Arabs provide more implicit and less specific explanations of their refusals than do native English speakers. The analysis revealed that the respondents used indirect semantic formulas and false excuses as refusal strategies. No direct explanation was given. The

Table 5. Frequency of refusal strategy use

\begin{tabular}{|c|c|c|}
\hline Semantic formulas & Strategy & Frequency \\
\hline \multirow[t]{2}{*}{ Direct Refusal } & Negative ability & 83 \\
\hline & No & 15 \\
\hline \multirow[t]{15}{*}{ Indirect refusal } & Explanation & 277 \\
\hline & Apology & 171 \\
\hline & Postponement & 45 \\
\hline & $\begin{array}{l}\text { Statement of } \\
\text { alternative }\end{array}$ & 21 \\
\hline & Promise & 13 \\
\hline & $\begin{array}{l}\text { Conditional } \\
\text { acceptance }\end{array}$ & 11 \\
\hline & $\begin{array}{l}\text { Attempt to dissuade } \\
\text { interlocutor } \\
\text { - criticize the } \\
\text { requester }\end{array}$ & 10 \\
\hline & $\begin{array}{l}\text { Acceptance } \\
\text { functioning as a } \\
\text { refusal } \\
\text { - lack of enthusiasm }\end{array}$ & 8 \\
\hline & $\begin{array}{l}\text { Attempt to dissuade } \\
\text { the interlocutor } \\
\text { - negative } \\
\text { consequence }\end{array}$ & 5 \\
\hline & Statement of principle & 5 \\
\hline & $\begin{array}{l}\text { Attempt to dissuade } \\
\text { the interlocutor } \\
\text { - let interlocutor off } \\
\text { the hook }\end{array}$ & 4 \\
\hline & Wish & 3 \\
\hline & $\begin{array}{l}\text { Avoidance } \\
\text { - postponement }\end{array}$ & 2 \\
\hline & $\begin{array}{l}\text { Avoidance } \\
\text {-silence }\end{array}$ & 2 \\
\hline & $\begin{array}{l}\text { Request for additional } \\
\text { information }\end{array}$ & 1 \\
\hline \multirow[t]{7}{*}{ Adjuncts to Refusals } & Agreement & 33 \\
\hline & $\begin{array}{l}\text { Gratitude adjuncts } \\
\text { gratitude }\end{array}$ & 32 \\
\hline & $\begin{array}{l}\text { Statement of positive } \\
\text { opinion }\end{array}$ & 29 \\
\hline & Willingness & 27 \\
\hline & Pause fillers & 8 \\
\hline & Statement of empathy & 4 \\
\hline & Preparatory & 1 \\
\hline
\end{tabular}


Table 6. Frequency of complaint strategy use

\begin{tabular}{llc}
\hline Category & Strategy & Frequency \\
\hline & Str. 1 Opting out & 9 \\
$\begin{array}{l}\text { Cat. 1 No explicit } \\
\text { reproach }\end{array}$ & Str. 2 Hints & 85 \\
$\begin{array}{l}\text { Cat II. Expression } \\
\text { of disapproval }\end{array}$ & $\begin{array}{l}\text { Str. 3 Annoyance } \\
\text { Str. 4: Ill } \\
\text { consequences }\end{array}$ & 43 \\
Cat. III. Accusation & $\begin{array}{l}\text { Str. 5: Indirect } \\
\text { Str. 6: Direct }\end{array}$ & 1 \\
& Str. 7: Modified \\
bat. IV: Blame & $\begin{array}{l}\text { Str. 8: Explicit } \\
\text { blame (behavior) } \\
\text { Str. 9: Explicit } \\
\text { blame (person) }\end{array}$ & 19 \\
& $\begin{array}{l}\text { Str. 10: Request } \\
\text { for repair }\end{array}$ & 17 \\
Str. 11: Threat. & 76 \\
Cat. V: Directive & 24 \\
acts & & \\
\hline
\end{tabular}

sample tended to soften their refusals because a refusal is a face-threatening act. This was evident in a situation where they were asked to refuse a professor's request. In situation 3 (invitation for lunch), responses included "I am sorry, I have something urgent to do"; "My brother has a health problem and I have to leave quickly"; and "I have an urgent meeting." One explanation for this is that the respondents wanted to be more polite and not refuse the invitation for insignificant reasons, because the professor had a high status and deserved respect, as evidenced by the students' use of expressions such as "it is an honor for me, professor"; "it is very kind of you, professor"; "I am really happy"; and "it is a great idea." These expressions are adjuncts to refusals that express a willingness to accept before an apology, which may be influenced by cultural values. By comparison, NSs in similar learning environments believe that their right to refuse outright is a characteristic of their individualistic culture, whereas Jordanian culture (and Arabic culture in general) is based on a collectivism in which groups, group harmony, and social hierarchy are more important (Huwari and Al-Shboul, 2015). However, the respondents tended to be more direct with their refusals if their interlocutor was a friend or family member. For example, in situation 8 (borrowing notes), responses included "No, why didn't you write any notes?"; "No, take someone else's notes"; "Sorry, I can’t give you my notes"; "Take the notes from another good student"; and "No, I don't accept your request because I have a quiz and I need to study."

Postponement was another refusal strategy used by the sample in the current study, similar to Ghazanfari et al. (2013), in which the Persian sample used postponement to refuse invitations, suggestions, or offers more often than the NSs did. In situation 7 (a tutor asked you to do a presentation), all the respondents asked for another chance to do the presentation because they were busy. This contradicts Alemi and Tajeddin's (2013) finding that NNSs tend more than NSs do to offer suitable apologies or excuses following their refusals.

Having limited opportunities for interaction in English, EFL learners may not produce adequate semantic formulas due to a lack of knowledge (Kasper, 1997, cited in Tanck, 2002). NNSs, in contrast to NSs, sometimes produce utterances that are less appropriate for the situation when performing speech acts (Tanck, 2002).

Regarding the complaint findings, the results were similar to Bikmen and Marti (2013), in which expressions of hints, requests, and annoyance were the preferred complaint strategies. The Jordanian sample performed these strategies quite often because they are less direct and more polite. Another compelling finding is that, in most situations, the respondents did not perform mild complaint strategies or openers. In situation 9 (a professor forgot to mark your assignment), for example, the respondents produced utterances such as "Professor, I want to know my mark"; "Sorry for interrupting you, but I want to ask about the assignment"; and "May I know my mark?" In Bikmen and Marti (2013), the Turkish sample used indirect accusation and urgency, which was not the case with the NSs, who avoided conveying urgency in their utterances by using mild complaint strategies and openers. In situation 6 (driver splashed dirty water), one of the frequent strategies was blaming interlocutors in form of questions. The respondents produced utterances such as "Are you stupid?"; "Where are your eyes?"; "Where is your license?"; "Give me the number of your father"; "Why did you splash dirty water on me (like you) [dirty person]? I will hit you"; and "Didn't you see me?" Similarly, in Bikmen and Marti (2013), the Turkish sample used rhetorical questions to indicate modified blame, whereas the NSs generally expressed their modified blame with imperatives.

Notably, one of the semantic formulas used to express complaints was the use of swear words. Swearing is common in Arabic culture, and it is used to convince an interlocutor of the truth of one's speech. Some religious words were also used in situation 5 (angry father) "If God is willing to give you anything, you will get it in the end...I have faith in Allah (God)"; "Have some faith, dad"; and "This is my destiny". Again, these words were used to convince the listener and assert the speaker's sincerity.

There was also strong evidence of negative pragmatic transfer observed in the Jordanian EFL learners in this study. In many situations, the students produced utterances similar to those used in their L1. For example, in refusal situation 1 (broken vase), the following expressions were used: "It's my favorite vase. Why weren't you careful when you cleaned it?"; "I cannot accept your apology"; "I will not forgive you"; "It is from my dear friend"; "Get out and leave me alone"; "Buy a new one as soon as possible"; and "I don't want you to clean my office next time". In complaint situation 10, responses such as "If you don't stop the party, I will bring a gun and I will kill you and your family" show the influence of Arabic culture of being more strict on the performance of this speech act.

The students were quite often found to define relationships (one of the categories added by Al-Issa, 2003) when making refusals: "Oh dear friend, I am sorry, I am afraid I will make 
you late every day"; "Sorry, my professor"; "I am sorry, my colleague." The same was true of complaints: "Hey, dear friend"; "Don't worry, my father"; "Please, my father"; and "my lovely sister." Using these relationship-defining formulas is a strategy for showing respect, gaining the approval of interlocutors, and developing an aspect of socialization. An expression particular to this context is a request for understanding: "My father, please understand me"; "My father, I don't understand why you don't believe me"; "Don't be angry, please"; and "if you don't believe me, come with me next time."

Moreover, the respondents provided more detailed semantic formulas when addressing interlocutors of equal social status, such as friends, and their responses were shorter and more formal when addressing interlocutors of higher status, such as professors. In some studies (cf. Eshreteh, 2015), Americans have been found to use similar refusal strategies based on the status of the addressee.

\section{CONCLUSION}

The study aimed to investigate the refusal and complaint speech act strategies employed by Jordanian undergraduate EFL learners and to highlight the factors that govern their choice of language. The performance of the speech acts of refusal and complaint is similar in the distribution and strategies used. Although they differ in linguistic forms, the content of these speech acts is always influenced by the social and cultural norms of the speaker's L1 and L2. Although there exist general concepts and universal principles governing speech acts, strategy preferences are subject to the cultural norms associated with different societies. Regarding refusal strategies, as mentioned, the most frequently used refusal strategies involved an explanation or excuse, apology, negative ability, postponement, or adjuncts to refusals. The findings also revealed that EFL learners realize the speech act of complaint mostly through strategies such as expressing annoyance, accusation, and blame, as well as providing an alternative. These strategies manifest differently depending on the context of communication, in addition to the gender, social status and culture of the interlocutors. Various studies have shown that speech acts can be perceived differently by linguistically and culturally diverse groups; therefore, considering the significance of cultural values and norms is essential for understanding refusal and complaint strategies. It is recommended that instructors and teachers in an EFL context teach meaning as well as form, because EFL students need both linguistic and pragmatic competence to communicate effectively in English, especially regarding their lack of opportunities for communicating outside of school. Future studies should investigate more groups of varying levels of proficiency, and gender differences should also be examined. In addition, in future research, using naturally occurring data in real-life situations is also recommended.

\section{ACKNOWLEDGMENT}

I thank Al Hussein Bin Talal University for allowing me to conduct this research during my sabbatical.

\section{REFERENCE}

Alemi, M. \& Tajeddin, Z., (2013). Pragmatic rating of L2 refusal: Criteria of native and non-native English teachers. TESL Canada Journal, 30, 63-81.

Al-Issa, A. (2003). Sociocultural transfer in L2 speech behaviors: evidence and motivating factors. International Journal of Intercultural Relations, 27, 581-601.

Al-Shboul, Y., \& Huwari, I.F. (2016). A comparative study of Jordanian Arabic and American English refusal strategy. British Journal of English Linguistics, 4(3), 50-62.

Al-Shorman, A.R. (2016). Saudi and Jordanian Undergraduates' Complaining Strategies: A Comparative Intralanguage Educational Linguistic Study. Arabian World English Journal, 7(1), 203-228.

Austin, J. L. (1962). How to Do Things with Words. Harvard University Press, Cambridge.

Baba, J. (2010). Interlanguage Pragmatics Study of Indirect Complaint among Japanese ESL Learners. Online Submission, 7(12), 23-32.

Beebe, L. M., Takahashi, T., Uliss-Weltz, R. (1990). Pragmatic transfer in ESL refusals. In Scarcella, R, Andersen, E., Krashen, S.D., (Eds.), On the Development of Communicative Competence in a Second Language. Newbury House, New York.

Bikmen, A., \& Marti, L. (2013). A study of complaint speech acts in Turkish learners of English. Education and Science, 38 (170), 253-265.

Chen, Y. S., Chen, C. Y. D., Chang, M. H. (2011). American and Chinese complaints: Strategy use from a cross-cultural perspective. Intercultural Pragmatics, 8(2), 253-275.

Eshreteh, K.M.M. (2015). Intercultural Pragmatics Revisited: Refusal Strategies and Politeness. Research Journal of English and Literature, 3(1), 180-192.

Flor, A. M., \& Juan, E. U. (2011). Research methodologies in pragmatics: Eliciting refusals to requests. Elia: Estudios de lingüística inglesa aplicada, 11, 47-88.

Cortijo, M.F. (2015). Refusals of offers by Catalan learners of English. TFG degree in English Studies, Universitat Autònoma de Barcelona.

Ghazanfari, M., Bonyadi, A., Malekzadeh, S. (2013). Investigating cross-linguistic differences in refusal speech act among native Persian and English speakers. International Journal of Research Studies in Language Learning, 2(4), 49-63.

House, J., \& Kasper, G. (1981). Politeness markers in English and German. In Coulmas, F., (ED.), Conversational Routine: Explorations in Standardized Communication Situations and Prepatterned Speech. Mouton, New York.

Huwari, I. F., \& Al-Shboul, Y. (2015). A Study on the Perception of Jordanian EFL Learners' Pragmatic Transfer of Refusals. Advances in Language and Literary Studies, 6(1), 46-54.

Kasper, G. (1992). Pragmatic transfer. Second Language Research, 8 (3), 03-231.

Kasper, G. (1997). Beyond reference. In Kasper, G., Kellerman, E. (Eds.), Communication Strategies: Psycholin- 
guistic and Sociolinguistic Perspectives. Addison Wesley Longman, New York.

Koczogh, H. V. (2012). The effects of gender and social distance on the expression of verbal disagreement employed by Hungarian undergraduate students. Unpublished Doctoral Dissertation. University of Debrecen, Debrecen.

Moaveni, H. T. (2014). A Study of Refusal Strategies by American and International Students at an American University. Master's thesis. Minnesota State University, Mankato.

Mofidi, M., \& Shoushtari, Z. G. (2012). A Comparative Study of the Complaint Strategies among Iranian EFL and ESL Students-The Study of the Effect of Length of Residence and the Amount of Contact. English Language Teaching, 5(11), 118.

Murphy, B., \& Neu, J. (1996). My grade's too low: The speech act set of complaining. In Gass, S.M., Neu, J. (Eds.), Speech Acts Across Cultures: Challenges to Communication in a Second Language. Mouton de Gruyter, Berlin.

Olshtain, E., \& Weinbach, L. (1987). Complaints: A study of speech act behavior among native and non-native speakers of Hebrew. In Verschueren, J., Bertucelli-Papi, M. (Eds.), The Pragmatic Perspective. John Benjamins: Amsterdam.
Olshtain, E., \& Weinbach, L. (1993). Interlanguage Features of the Speech Act of Complaining. In Kasper, G. and Blum-Kulka, S. (Eds.) Interlanguage Pragmatics. Oxford University Press, Oxford.

Ren, W. (2012). Pragmatic development in Chinese speakers' L2 English refusals. EUROSLA Yearbook, 12, 63-87.

Sattar, H. Q. A., Lah, S. C., Suleiman, R. R. (2011). Refusal strategies in English by Malay University students. GEMA: Online Journal of Language Studies, 11(3), 69-81.

Shokouhi, S., \& Rezaei, A. (2015). The importance of teaching pragmatics in the classrooms (focus on complimenting). Journal for the Study of English Linguistics, 3(1), 101-107.

Tanck, S. (2002). Speech act sets of refusal and complaint: A comparison of native and non-native English speakers' production. TESOL, American University, Washington, DC.

Tatsuki, D.H. (2000). If my complaints could passions move: An interlanguage study of aggression. Journal of Pragmatics, 32, 1003-1017.

Trosborg, A. (1995). Interlanguage Pragmatics: Requests, Complaints and Apologies. Mouton de Gruyter, Berlin.

Zhang, D. (2001). The speech act of complaining: a cross cultural comparative study of Chinese and American English speakers. Master's Thesis, Iowa State University. 